\title{
ANALISIS PEMAHAMAN GURU TERHADAP CAPAIAN STANDAR PEMBIAYAAN DI TINGKAT SMP/MTS DI KABUPATEN BANDUNG
}

\author{
Muhamad Ihsan Hasanudin, Chaerul Rochman, Ida Farida, Hasan Basri dan \\ Mohamad Erihadiana \\ Universitas Islam Negeri Sunan Gunung Djati Bandung, Indonesia \\ Email: mihsanhasanudin@gmail.com, chaerulrochman99@uinsgd.ac.id, \\ farchemia65@uinsgd.ac.id, hasanbasri@uinsgd.ac.id dan \\ erihadiana@uinsgd.ac.id.
}

\begin{abstract}
One of the ways to improve the quality of education is to fulfill financing standards. Funding in education is very important because it is related to infrastructure, human resource development and other educational components. In addition, teachers' understanding of financing standards is one of the most important factors in achieving financing standards. This study aims to determine the achievement of school financing standards for SMP / MTs through the understanding of Islamic education and non-Islamic education teachers of the standard indicators of financing. The method used is descriptive quantitative, the data obtained using observation, questionnaires and interviews. Data analysis was performed using simple statistical analysis and triangulation of the indicators with the lowest score. The sample used was 5 Islamic education teachers and 5 non-Islamic education teachers at the SMP / MTs level. The results showed that the percentage of understanding of Islamic Education teachers was $86 \%$ greater than the percentage of understanding of non Islamic Education teachers by $85 \%$. Based on the triangulation of the lowest indicators, the problem of financing standards includes gaps between budget planning and realization due to limited funds, and a lack of teacher involvement in planning investment funds for facilities and infrastructure.
\end{abstract}

Keywords: teacher's understanding; financing standards; quality of education

\begin{abstract}
Abstrak
Peningkatan mutu pendidikan salah satunya berkaitan dengan pemenuhan standar pembiayaan. Pembiayaan dalam pendidikan menjadi sangat penting disebabkan berkaitan dengan sarana prasarana, pengembangan sumberdaya manusia dan komponen pendidikan lainnya. Selain itu, Pemahaman guru terhadap standar pembiayaan menjadi salah satu faktor yang sangat penting dalam pencapaian standar pembiayaan. Penelitian ini bertujuan untuk mengetahui pencapaian standar pembiyaan sekolah tingkat SMP/MTs melalui pemahaman guru PAI dan non-PAI terhadap indikator Standar Pembiayaan. Metode yang digunakan adalah kuantitatif deskriptif, data yang diperoleh menggunakan teknik observasi, angket dan wawancara. Analisis data dilakukan dengan analisis statistik sederhana, dan triangulasi terhadap indikator dengan skor terendah. Sampel yang digunakan berjumlah 5 guru PAI dan 5 guru non-PAI di tingkat SMP/MTs. Hasil penelitian
\end{abstract}


menunjukan bahwa persentase pemahaman guru PAI $86 \%$ lebih besar dari persentase pemahaman guru non PAI sebesar $85 \%$. Berdasarkan triangulasi terhadap indikator terendah, bahwa permasalahan standar pembiayaan meliputi adanya kesenjangan antara perencanan dan realisasi anggaran yang disebabkan keterbatasan dana, dan kurangnya keterlibatan guru dalam perencanaan dana investasi sarana dan prasarana.

Kata kunci: pemahaman guru; standar pembiayaan; mutu pendidikan

Coresponden Author

Email: mihsanhasanudin@gmail.com Artikel dengan akses terbuka dibawah lisensi

\section{Pendahuluan}

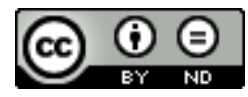

Mutu pendidikan menjadi salah satu indikator kemajuan suatu bangsa. Dengan demikian, Negara memiliki kewajiban menghadirkan layanan pendidikan yang bermutu bagi warga negara. Berbagai upaya dan strategi dilakukan oleh pemerintah dalam upaya peningkatan dan pemerataan mutu pendidikan di Indonesia, Salah satunya, pemerintah telah menyususun Standar Nasional Pendidikan melalui PP Nomor 19 tahun 2005. Standar nasional tersebut merupakan sebagai dasar dan arah dalam perencanaan, pelaksanaan dan pengawasan dalam praktik pendidikan agar menghasilkan layanan pendidikan yang bermutu dan berfungsi untuk mencapai tujuan Pendidikan nasional.

Peningkatan mutu pendidikan salah satunya berkaitan dengan pemenuhan standar pembiayaan. Menurut Nuraeti, formulasi penentuan kebutuhan pembiayaan dalam pendidikan menjadi faktor esensial dalam peningkatan mutu pendidikan (Hidayah \& Etty Susilowati, 2014). Pembiayaan pendidikan pada dasarnya merupakan suatu proses mengalokasikan sumber-sumber pada kegiatan-kegiatan atau program-program pelaksanaan operasional pendidikan atau dalam proses belajar mengajar di kelas (Matin, 2014). Pembiayaan dalam pendidikan menjadi sangat penting disebabkan berkaitan dengan sarana prasarana, pengembangan sumberdaya manusia dan komponen pendidikan lainnya.

Pembiayaan pendidikan merupakan tanggung jawab bersama antara pemerintah dan masyarakat. Dengan demikian, pemerintah dan masyarakat harus memahami dan menjalankan tugasnya agar pendidikan dapat berjalan dengan baik. Berdasarkan amanat konstitusi bahwa pemerintah pusat dan pemerintah daerah bertanggung jawab untuk alokasi anggaran pendidikan sebesar 20\% dari APBN dan APBD. Hal tersebut, sangat berkaitan erat dengan tugas dan tanggung jawab negara untuk menjamin dan menyediakan pendidikan yang bermutu bagi warga negara. Berdasarkan data dari Neraca Pendidikan Daerah, pada APBD 2019 hanya terdapat 4 provinsi dan $22 \mathrm{kab} / \mathrm{kota}$ yang telah merealisasikan 20\% APBD untuk biaya pendidikan. Menurut Syaiful Huda, hasil evaluasi komisi X DPR menunjukan bahwa realisasi APBD untuk dana pendidikan hanya memiliki rata-rata 8-9\% dari total APBD (Nainggolan, 2020). 
Muhamad Ihsan Hasanudin, Chaerul Rochman, Ida Farida, Hasan Basri, dan Mohamad Erihadiana

Persoalan sumber dana tersebut menjadi tantangan yang harus dihadapi lembaga pendidikan di Indonesia. Hasil Penelitian OECD (the Organization for Economic Coperation and Development) tentang sumber dana pendidikan yang dilakukan kepada kepala sekolah negeri dan swasta di Indonesia dan 64 negara lainnya menunjukan bahwa sumber dana pendidikan sebesar $85 \%$ dari pemerintah, 10 persen dari orangtua siswa, masing-masing 2\% dari donatur dan pihak lainnya (Noval \& Irawan, 2019). Selain itu, persoalan pembiayaan juga ditemukan dalam proses manajemen biaya pendidikan. Sekolah tidak melaksanakan perencanaan, pelaksanaan dan pengawasan dengan baik, di antaranya masih ada sekolah yang kesulitan dalam penyusunan RKA.

Untuk pemenuhan standar pembiyaan, sekolah harus memiliki kemampuan mengelola pembiyaan pendidikan dengan baik dan sesuai kebutuhan sekolah untuk pemenuhan dan peningkatan mutu standar pembiayaan. Selain itu, Pemahaman guru terhadap standar pembiayaan menjadi salah satu faktor yang sangat penting. Guru akan terlibat dalam proses penyusunan RKA dan juga akan dituntut untuk membantu realisasi strategi dan tindakan yang telah ditetapkan oleh kepala sekolah untuk pemenuhan standar dan peningkatan mutu. Maka secara moral, guru akan senang dapat bekerja di sekolah yang diakui sebagai sekolah bermutu. Penelitian ini bertujuan untuk mengetahui pencapaian standar pembiyaan sekolah tingkat SMP/MTs melalui pemahaman guru PAI dan non-PAI terhadap indikator Standar Pembiayaan. Penelitian ini diharapkan dapat memberikan sumbangan ilmu pengetahuan, khususnya manajemen pembiayaan pendidikan, sehingga guru dan pengelola sekolah mampu bekerjasama untuk mencapai atau melampaui standar pembiayaan.

\section{Metode Penelitian}

Penelitian ini menggunakan metode kuantitatif deskriptif, data yang diperoleh dari sampel populasi yang di analisis sesuai dengan metode statistik yang digunakan dan bermaksud untuk mengetahui pemahaman guru terhadap capaian standar pembiayaan secara kuantitatif. Pengambilan data di lakukan dengan angket dan observasi, sedangkan sampel yang digunakan berjumlah 5 guru Pendidikan Agama Islam, dan 5 guru nonpendidikan Agama Islam.

Instrumen yang digunakan adalah angket tentang pemahaman terhadap standar pembiayaan yang berjumlah 16 butir indikator. Adapun indikator tersebut meliputi; 1) sekolah memiliki Rencana Kerja Anggaran yang memuat alokasi anggaran untuk investasi, 2) sekolah memiliki Rencana Kerja Anggaran yang memuat alokasi anggaran non-personalia, 3) sekolah memiliki dokumen investasi sarana dan prasarana secara lengkap, 4) sekolah membelanjakan biaya untuk pengembangan pendidik dan tenaga kependidikan, 5) sekolah merealisasikan modal kerja sesuai dengan RKA, 6) Sekolah/madrasah menyampaikan biaya operasional untuk guru dan tenaga kependidikan, 7) sekolah merealisasikan rencana belanja anggaran pengadaan alat tulis sesuai dengan RKA, 8) sekolah merealisasikan pengadaan bahan dan alat habis pakai untuk pembelajaran sesuai RKA, 9) sekolah merealisasikan pemeliharaan dan perbaikan sarana dan prasaran secara berkala sesuai dengan RKA, 10) sekolah mereliasasikan 
biaya pengadaan daya dan jasa sesuai dengan RKA, 11) sekolah merealisasikan biaya transportasi dan perjalanan dinas serta konsumsi, 12) sekolah mereliasasikan anggaran biaya kegiatan pembinaan siswa, 13) sekolah membelanjakan angaran untuk biaya pelaporan, 14) sekolah mengelola sumbangan Pendidikan secara sistematis, tranparan, efesien dan akuntabel, 15) sekolah memiliki pembukuan keuangan yang lengkap, 16) sekolah meiliki laporan pertanggung jawaban yang disosialiasikan kepada yayasan dan orangtua siswa.

Data yang diperoleh kemudian dilakukan penentuan skor dengan skala ordinal 1-4 dengan ketentuan, yaitu; nilai $1=$ kurang, nilai $2=$ Cukup, nilai $3=$ baik, dan nilai $4=$ Unggul. Dengan demikian, maka jumlah skor maksimum adalah enam puluh empat (64). Persentase ketercapaian $=($ Perolehan skor: Skor Maksimum $)$ X 100\% . Berikut adalah tabel penentuan kualifikasi persentase ketercapaian pemahaman guru terhadap capaian standar pembiayaan:

Tabel 1

Kualifikasi Persentase Ketercapaian

\begin{tabular}{ccc}
\hline NO & Persentase & Kualifikasi \\
\hline 1 & $90 \%-100 \%$ & Unggul \\
\hline 2 & $80 \%-89.99 \%$ & Baik \\
\hline 3 & $70 \%-79.99 \%$ & Cukup \\
\hline 4 & $60 \%-69.99 \%$ & Kurang \\
\hline 5 & Kurang dari $59.99 \%$ & Sangat Kurang \\
\hline
\end{tabular}

Sumber: (Sudjana, 2009)

Setelah diperoleh analisis data berdasarkan penentuan skor dan rata-rata persentase, maka dilanjutkan triangulasi terhadap indikator-indikator yang belum maksimal dengan cara melakukan wawancara untuk menayanakan permasalahan yang dihadapi dan penentuan solusi untuk pemecahan masalah tersebut.

\section{Hasil dan Pembahasan}

1. Profil Pemahaman Guru PAI dan non-PAI terhadap Capaian Indikator Standar Pembiayaan

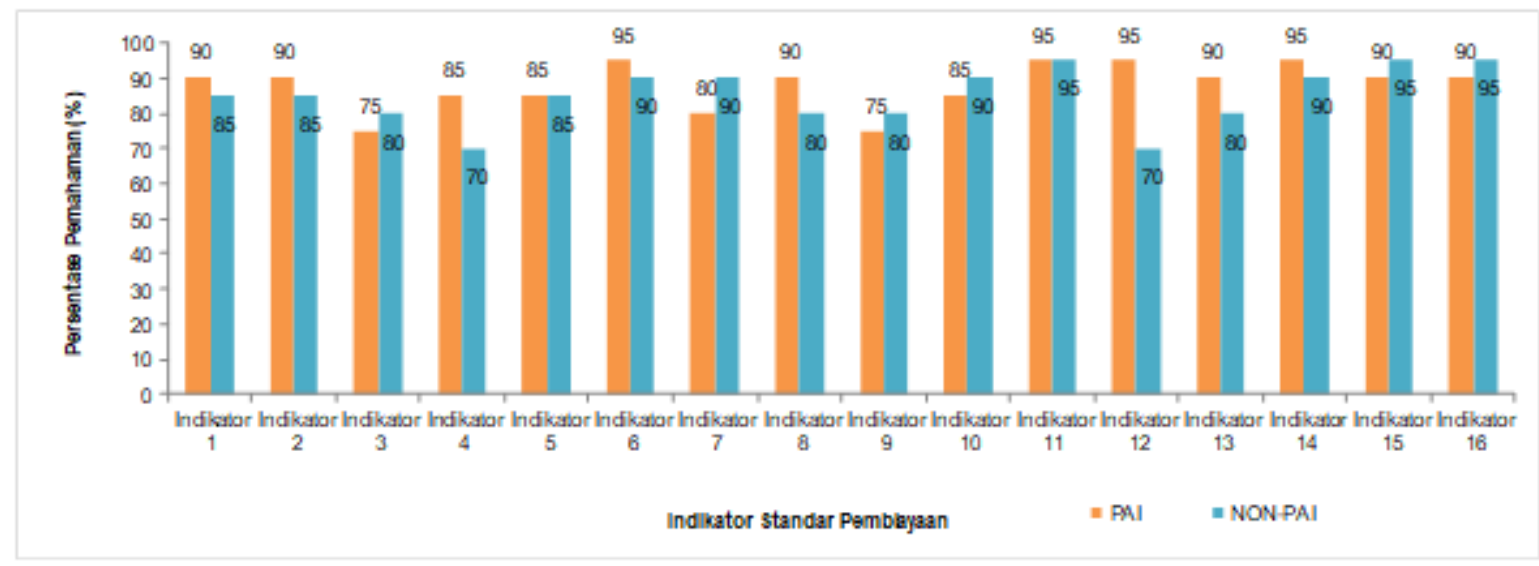

\section{Gambar 1}

Profil Perbandingan Pemahaman Guru PAI dan Non-PAI terhadap Capaian Standar Pembiayaan 
Muhamad Ihsan Hasanudin, Chaerul Rochman, Ida Farida, Hasan Basri, dan Mohamad Erihadiana

Berdasarkan gambar 1 bahwa perolehan skor pemahaman guru terhadap capaian standar pembiayaan sangat variatif. Persentase tertinggi pemahaman guru PAI sebesar $95 \%$ berada pada indikator $6,11,12$, dan 14. Ketiga indikator tersebut berkaitan dengan ketersedian biaya operasional untuk pendidik dan tenaga kependidikan, ketersediaan biaya transportasi dan perjalanan dinas, realisasi anggaran dan pengelolaan sumbangan biaya Pendidikan. Sedangkan persentase tertinggi pemahaman guru non-PAI sebesar 95\% berada pada indikator 11 dan 16 tentang ketersediaan biaya transportasi dan perjalanan dinas, dan sekolah memiliki laporan pertanggungjawaban pembiayaan yang disampaikan kepada yayasan/pemerintah dan orangtua.

Indikator pemahan guru PAI dengan nilai terendah sebesar $75 \%$ berada pada indikator 3 dan 9. Indikator tersebut menjelaskan tentang ketersediaan dokumen investasi sarana dan prasarana, kesesuaian realisasi anggaran pemeliharaan sarana dan prasarana secara berkala. Sedangkan skor persentase terendah pemahaman guru non-PAI sebesar $70 \%$ berada pada indikator 4 dan 12 yang menjelaskan tentang kesesuain realisasi biaya pengembangan pendidik dan tenaga kependidikan, serta realisasi biaya pengembangan dan pembinaan siswa.

Profil guru PAI dan non-PAI belum secara utuh memahami setiap butir indikator standar pembiayaan. Indikator yang belum dipahami secara optimal oleh guru PAI yaitu indikator 3 dan 9 yang menjelaskan realisasi biaya investasi dan pemeliharan sarana prasarana. Ketersediaan sarana dan prasarana menjadi salah satu komponen penting dalam sistem pendidikan yang secara langsung dan tidak langsung dapat mewujudkan tujuan pendidikan (Hartoni, 2018). Biaya investasi sarana pendidikan merupakan anggaran yang dialokasikan untuk pengadaan dan pembangunan sarana dan prasarana pendidikan yang masa pemanfaatan dan penggunaannya lebih dari satu tahun. Ghozali memperinci BSP Investasi sarana dan prasarana menjadi kelompok besar komponen sbb: (1) bangunan 30,62\% - 38,95\%, (2) perabot $20,43 \%-27,08 \%$, (3) peralatan $14,38 \%-25,36 \%$, (4) lahan $12,27 \%$ $17,76 \%$ (Ghozali, 2012). Investasi sarana dan prasarana yang dilakukan oleh pihak sekolah nantinya benar-benar akan mampu menghadirkan fasilitas pendidikan yang refresentatif dan mempermudah proses pembelajaran yang berpengaruh terhadap hasil belajar siswa. Menurut (Miski, 2017) bahwa ketersediaan dan kualitas sarana prasarana berkontribusi sebesar 42,26\% terhadap hasil belajar siswa (Miski, 2017).

Realisasi Anggaran pemeliharan sarana dan prasarana menjadi salah satu bagian dari proses manajemen sarana prasarana. Kegiatan pemeliharan sarana prasarana merupakan upaya yang dilakukan untuk tetap menjaga kualitas dan kondisi yang baik dan siap digunakan dalam proses pendidikan. Pemeliharan sarana dan prasarana yang dilakukan secara kontinu dapat membantu untuk menekan pembiayaan serta mampu mengurangi resiko kerusakan berat. Pemeliharan sarana dan prasarana harus dilakukan dengan manajemen yang baik dengan meliputi 
perencanaan, pengorganisasian, pelaksanaan dan pengawasan (Suliyarti, 2019). Dalam pemeliharaan sarana dan prasarana, warga sekolah dan masyarakat sekitar harus mampu bekerja sama agar sarana dan prasarana tetap terjaga dengan baik dan dapat digunakan sesuai dengan fungsinya.

Indikator yang belum dipahami secara optimal oleh Guru non-PAI adalah indikator 4 dan 12 yang menjelaskan biaya pengembangan pendidik dan tenaga kependidikan serta biaya kegiatan pembinaan siswa. Pengembangan pendidik dan tenaga kependidikan merupakan sebuah upaya meningkatkan kompetensi dan produktivitas kerja pada tingkatan manajemen dan jenjang pendidikan (Purwanto., 2007) Upaya pengembangan pendidik dan tenaga kependidikan perlu adanya komitmen dari pimpinan sekolah, sehingga program pengembangan pendidik dan tenaga kependidikan selalu menjadi agenda penting yang harus dilakukan antara pimpinan sekolah dan pendidik serta tenaga kependidikan. Strategi pengembangan dapat dilakukan dengan beberapa Langkah yang meliputi 1) analisis kinerja pendidik dan tenaga kependidikan, 2) analisis kebutuhan pengembangan pendidik dan tenaga kependidikan, dan 3) analisi sumber daya (Illahi, 2020). Salah satu faktor yang akan mempengaruhi keberhasilan program pengembangan adalah biaya. Ketersediaan anggaran pengembangan akan berdampak pada perencanaan dan pelaksanan program pengembangan yang fisibel dan realistis. Sedangkan menurut D. Suhardi (2010) bahwa kegiatan pembinaan siswa merupakan program khusus di luar jam pelajaran yang dilaksanakan secara sistematis oleh pihak sekolah untuk membantu peserta didik dalam mengembangkan kepribadian, karakter, minat dan bakat. (Fufindo, 2020) kegiatan pengembangan siswa/peserta didik sangat penting dilakukan untuk optimalisasi peran sekolah dalam meningkatkan prestasi peserta didik baik prestasi akademik maupun non-akademik. Dengan demikian, setiap kegiatan dan program sangat penting untuk direncanakan dalam Rencana Kerja Anggaran, hal ini salah satunya berkaiatan dengan ketersediaan dana. Dengan ketersediaan dan dukungan pendanaan yang sesuai dengan kebutuhan, ketercapaian kegiatan dan program sangat besar. Selain itu, penyusunan rencana kerja anggaran harus melibatkan semua pemangku kepentingan agar menghindari kesalahpahaman dalam pelaksanaan rencana kerja anggaran (Mursilah, 2015).

Berdasarkan hasil analisis di atas, menunjukan bahwa persentase profil pemahaman guru PAI dan non-PAI menunjukan kualifikasi baik, hal tersebut ditandai dengan 12 dari 16 jumlah indikator standar pembiayaan yang memiliki persentase di atas $80 \%$. Sedangkan 4 indikator lainnya memiliki nilai persentase di bawah $80 \%$ yang menunjukan kualifikasi cukup. Dengan demikian, pihak sekolah dan pemerintah secara bersama-sama harus mampu berkolaborasi untuk memenuhi standar pembiayaan agar memberikan layanan pendidikan yang bermutu. 
Muhamad Ihsan Hasanudin, Chaerul Rochman, Ida Farida, Hasan Basri, dan Mohamad Erihadiana

\section{Perbandingan Persentase Responden terhadap Capaian Standar Pembiayaan}

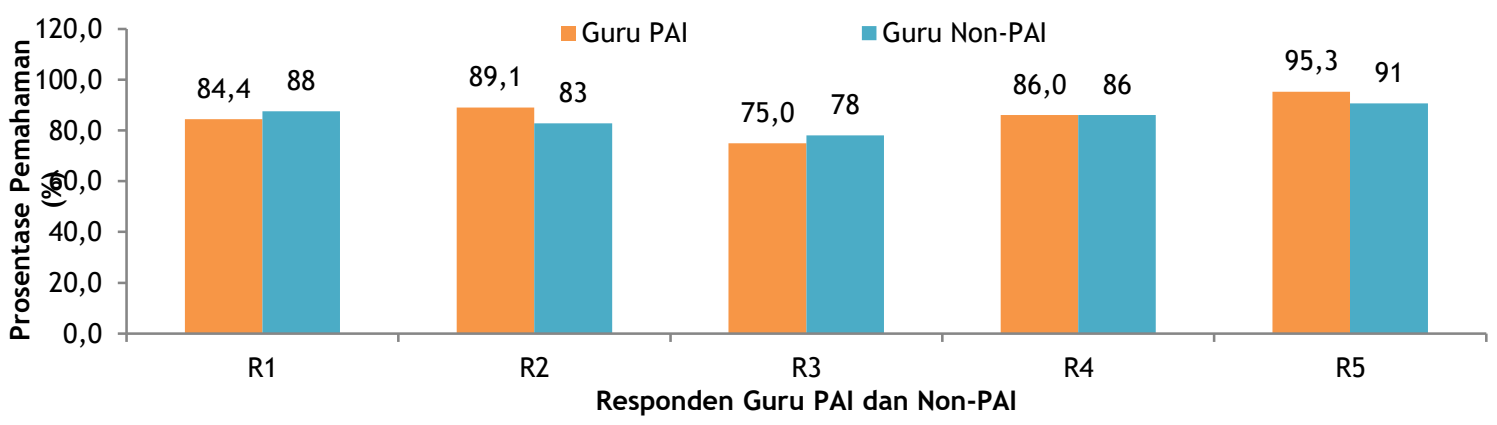

\section{Gambar 2 Perbandingan Persentase Pemahaman Standar Pembiayaan berdasarkan Responden}

Berdasarkan gambar 2 diperoleh pemahaman berdasarkan responden dengan persentase tertinggi sebesar $95,3 \%$ dan persentase terendah $75 \%$, kedua persentase tersebut diperoleh responden nomor 5 dan 3 dari guru PAI. Berdasarkan persentase ketercapaian tersebut dapat disimpulkan bahwa 4 responden dari masing-masing guru PAI dan non-PAI lebih dari $80 \%$ yang menunjukan bahwa pemahaman terhadap capaian standar pembiayaan memiliki kualifikasi baik. Sedangkan 1 responden dari masing-masing guru PAI dan non-PAI memiliki nilai persentase kurang dari $80 \%$ yang menunjukan bahwa pemahaman terhadap capaian standar pembiayaan memiliki kualifikasi cukup.

Adapun pemahaman terhadap capaian standar pembiayaan berdasarkan ratarata persentase guru PAI dan non-PAI dapat dilihap pada gambar 3.

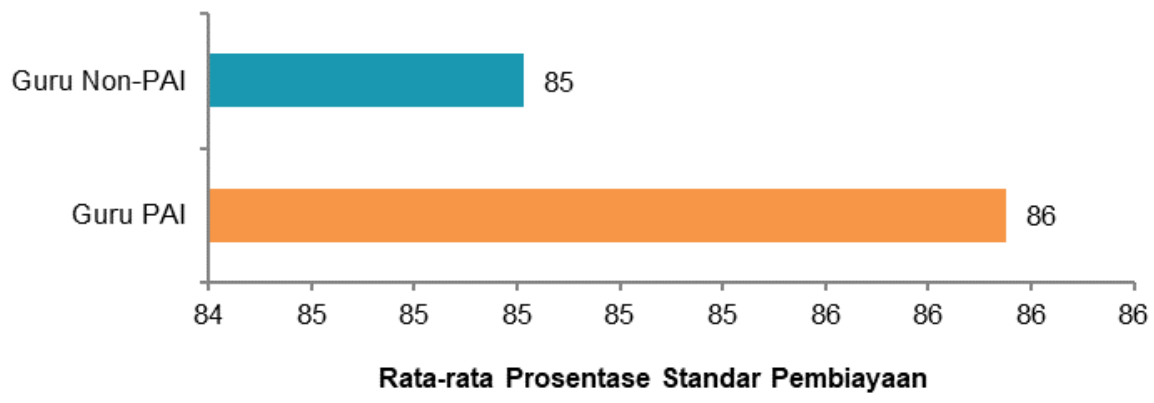

\section{Gambar 3 Perbandingan Rata-Rata Pemahaman Standar Pembiayaan}

Berdasarkan gambar 3 menunjukan perbandingan pemahaman terhadap standar pembiayaan dalam kategori kelompok guru bahwa persentase pemahaman guru PAI sebesar $86 \%$ lebih besar dari pada persentase pemahaman guru non-PAI yang memiliki skor $85 \%$, dan keduanya lebih besar dari $80 \%$ yang termasuk kategori baik.

Perbandingan persentase pemahaman terhadap standar pembiayaan berdasarkan kelompok guru terlihat bahwa guru PAI lebih memahami terhadap standar pembiayaan. Tetapi, pemahaman berdasarkan kelompok responden masih 
terdapat responden ke-3 dari masing-masing kelompok guru PAI dan non-PAI yang memiliki nilai cukup. Kedua responden tersebut harus mendapatkan evaluasi dan bimbingan terkait pemahaman terhadap capaian standar pembiayaan. Karena efektivitas pembiayaan pendidikan dapat terlaksana jika ada Kerjasama dan kolaborasi antara Yayasan/pemerintah, sekolah, dan masyarakat yang di dalamnya termasuk guru, sehingga keterbukaan, partisipasi, dan akuntabilitas dalam pengelolaan pembiayaan pendidikan dapat diwujudkan dalam kegiatan perencanaan, pelaksanaan dan pengawasan (Ferdi, 2013).

\section{Analisi Kesulitan Ketercapaian Standar Pembiayaan}

Triangulasi dilakukan untuk mendalami masalah penelitian, serta mencari penyebab dan solusi standar pembiayaan. Berdasarkan hasil analisis di atas, tringulasi dilakukan terhadap responden nomor 3 dari kelompok PAI dan no PAI. Responden nomor 3 dari kelompok PAI memiliki skor terkecil pada indikator ke 3 dan 9, sedangkan responden nomor 3 dari kelompok guru non-PAI memiliki skor terkecil pada indicator ke 4 dan 12 .

Berdasarkan hasil triangulasi Indikator ke 3 dan 9 yang dilakukan terhadap responden nomor 3 dari kelompok guru PAI menyatakan bahwa indikator ke-3 tidak terpenuhi karena guru tidak terlibat dalam perencanaan sehingga tidak mengetahui keberadaaan dan kelengkapan dokumen investasi sarana dan prasarana. Oleh karenanya, Yayasan dan pimpinan sekolah harus melibatkan semua pemangku kepentingan dalam perumusan investasi sarana dan prasarana, karena keterlibatan guru dan semua pemangku kepentingan akan mampu menghasilkan investasi sarana dan prasarana yang tepat guna. Misalnya, dalam perencanaan investasi sarana pembelajaran, guru akan lebih memahami sarana yang sangat dibutuhkan untuk mempermudah proses pembelajaran dan mencapai tujuan pembelajaran. Dalam hal ini, Yayasan, pimpinan sekolah dan warga sekolah secara bersama-sama harus mampu berkolaborasi untuk mencapai indikator standar tersebut. Sedangkan indikator ke 9 belum optimal disebabkan adanya kesenjangan antara rencana anggaran dengan kebutuhan anggaran dalam pelaksanaan pemeliharan sarana dan prasarana. Dengan demikian, dalam penyusunan RKA, pihak sekolah harus mampu melakukan analisis terhadap kondisi objektif sekolah baik secara mikro maupun makro, sehingga dengan kondisi tersebut sekolah akan mampu menentukan program kegiatan sekolah yang efektif dan efesien berdasarkan kemampuan anggaran sekolah. Dalam penyusunan RKA sekolah sebaiknya melakukan Langkah sebagai berikut: 1) Melakukan Evaluasi Diri sekolah (EDS) dengan melibatkan semua warga sekolah. 2) Melakukan Akumulasi isian EDS dan menyusun rekomendasi. 3) Menyusun draft RKAS, RKA berdasarkan skala prioritas hasil analisis ketercapaian Standar Nasional Pendidikan. 4) Malakukan Sosialisasi draft RKAS dan RKA bersama seluruh warga sekolah. 5) Forum Group DisucusionI draft RKAS dan RKA bersama seluruh warga sekolah. 6) Melakukan pengesahan dan sosialisasi RKA. 7) Menyediakan fasilitas untuk penyampaian saran 
Muhamad Ihsan Hasanudin, Chaerul Rochman, Ida Farida, Hasan Basri, dan Mohamad Erihadiana

pengelolaan pembiayaan sekolah. 8) Tim Pengembangan sekolah melakukan monitoring dan evaluasi sesuai siklus penjaminan mutu (Soemanto, 2015).

Triangulasi terhadap indikator ke 4 dan 12 dilakukan kepada responden nomor 3 dari kelompok guru non-PAI. Berdasarkan penjelasan responden nomor 3 dari kelompok guru non-PAI, bahwa realisasi dan penggunaan dana pengembangan dan pembinaan siswa, pendidik dan tenaga pendidikan terhambat dengan keterbatasan dana yang dimiliki sekolah. Masalah yang dihadapi sekolah dalam pembiayaan pendidikan, bukan saja masalah sumber dana, juga masalah alokasi dan penggunaan dana, sehingga besaran biaya pendidikan yang ditanggung oleh sekolah harus dilimpahkan kepada siswa. Dengan demikian, sekolah harus mampu menentukan alokasi dan sumber dana dengan tepat, dan memeperhatikan ketentuanketentuan dari penyandang dana sehingga tidak menutup kemungkinan ada program kegiatan sekolah yang dibiayai dengan subsidi silang. Selain itu kepala sekolah dan unit kerja terkait harus mamiliki kemampuan dalam menggali dana dari pihak luar. Selain itu, untuk mengatasi keterbatasan dana pengembangan pendidik, tenaga kependidikan dan siswa. Sekolah dapat melakukan kerjasama dengan perguruan tinggi untuk melakukan kegiatan pengabdian yang bertujuan mengembangkan kompetensi pendidik dan tenaga kependidikan, juga dapat melakukan optimalisasi peran alumni dalam kegiatan pengembangan siswa. Dengan demikian, sekolah harus menyusun program pendanaan secara matang dan mampu menggunakan dana pada sektor-sektor yang benar-benar dibutuhkan oleh sekolah.

\section{Kesimpulan}

Berdasarkan hasil temuan dan pembahasan bahwa profil pemahaman guru PAI dan non-PAI terhadap capaian standar pembiayaan menunjukan kategori baik, tetapi satu responden dari masing-masing kelompok guru belum memahami beberapa indikator standar pembiayaan. Malasah pembiayaan yang dihadapi sekolah bukan saja sumber dana, juga alokasi dana. Dengan demikian, strategi defensive menjadi salah satu alternatif yang dapat digunakan untuk menggunakan peluang dengan cara sekolah harus mampu menggunakan dana yang tersedia dengan memperhatikan skala prioritas untuk peningkatan standar mutu pendidikan. Selain itu, guru harus mampu meningkatkan pemahaman terhadap standar pembiyaan agar mampu bekerja sama dengan warga sekolah lainnya dalam pencapaian standar pembiyaan. 


\section{BIBLIOGRAFI}

Ferdi, W. P. (2013). Pembiayaan pendidikan: Suatu kajian teoritis. Jurnal Pendidikan Dan Kebudayaan, 19(4), 565-578.

Fufindo, Oscar Gare. (2020). Pembinaan kesiswaan di sekolah menengah pertama negeri kecamatan sungayang kebupaten tanah datar. Jurnal Bahana Manajemen Pendidikan, 1(1).

Ghozali, Abbas. (2012). Biaya Satuan Pendidikan Dasar dan Kebutuhan Dana untuk Pendidikan Dasar Gratis. Cakrawala Pendidikan, (1), 77195.

Hartoni, Hartoni. (2018). Impelementasi Manajemen Sarana Dan Prasarana Di Sekolah Menengah Kejuruan. Al-Idarah: Jurnal Kependidikan Islam, 8(1), 178-185.

Hidayah, Isti, \& Etty Susilowati, Sukirman. (2014). Analisis Pembiayaan Pendidikan SMA di Kota Semarang. Jurnal Riptek, 8(2), 13-22.

Illahi, Thomasna. (2020). Pembinaan dan Pengembangan Pendidik dan Tenaga Kependidikan.

Matin. (2014). Manajemen Pembiyaan Pendidikan: Konsep dan Aplikasinya. Jakarta: Rajawali Pers.

Miski, Rihatul. (2017). Pengaruh Sarana Dan Prasarana Terhadap Hasil Belajar Siswa. Tadbir Muwahhid, 4(2).

Mursilah, Mursilah. (2015). Manajemen Kesiswaan dan Manajemen Keuangan di SMA. Manajer Pendidikan, 9(3).

Nainggolan, Sri Yanti. (2020). Hanya Empat Daerah yang Alokasikan Anggaran Pendidikan $20 \%$.

Noval, Ahmad, \& Irawan, Irawan. (2019). Manajemen Pembiayaan Pendidikan di Madrasah Tsanawiyah Swasta: Studi kasus di MTs. Wihdatul Fikri Kab. Bandung. Manajemen Pendidikan, 14(1), 73-81.

Purwanto. (2007). Administrasi Pendidikan. Suka Jaya.

SOEMANTO, Soemanto. (2015). Strategi Pengelolaan Keuangan Di SMP Negeri 4 Ngadirojo Pacitan. Universitas Muhammadiyah Surakarta.

Suliyarti, Riri. (2019). Manajemen Pemeliharaan Sarana Dan Prasarana Pendidikan Untuk Meningkatkan Kualitas Pendidikan.

Sudjana. (2009). Metode Statistika. Bandung: Tarsito. 